\title{
Multi Machine Power System Stability Enhancement Using Static Sychronous Series Compensator (SSSC)
}

\author{
G Srikanth $^{\text {a }}$, Dr. A A Ansari ${ }^{\text {b }}$ \\ a Research Scholar, Dept. of Electrical \& Electronics Engineering, \\ Sri Satya Sai University of Technology \& Medical Sciences, Sehore, Bhopal Indore Road, Madhya Pradesh, India \\ ${ }^{\mathbf{b}}$ Research Guide, Dept. of Electrical \& Electronics Engineering, \\ Sri Satya Sai University of Technology \& Medical Sciences, Sehore, Bhopal Indore Road, Madhya Pradesh, India
}

Article History: Received: 11 January 2021; Accepted: 27 February 2021; Published online: 5 April 2021

\begin{abstract}
These days, the requirement for flexible and quick power stream control in the transmission framework is foreseen to increment later on taking into account utility liberation and power wheeling prerequisite. Diminishing the compelling reactance of lines by series remuneration is an immediate approach to build transmission ability. Nonetheless, power move capacity of long transmission lines is restricted by dependability contemplations. On account of the power electronic exchanging abilities as far as control and fast, more focal points have been done in FACTS gadgets regions and presence of these gadgets in transient security during transient flaws bringing about progress in power framework solidness. In this examination, a static synchronous series compensator (SSSC) is utilized to research the impact of this gadget in controlling active and reactive powers just as damping power framework motions in transient mode. The Proportional-Integral Controller (PI) controller is utilized to tune the circuit and to give the zero sign blunder. Static Synchronous Series Compensator (SSSC) is series reactive power remuneration to a power framework. The yield of a SSSC is series infused voltage, which leads or slacks line current by $90^{\circ}$, in this manner copying a controllable inductive or capacitive reactance. SSSC can be utilized to lessen the line impedance and upgrade the active power move ability of the line. With the boundaries and control, the SSSC is discovered successful to direct load voltage during abrupt difference in the heaps. The SSSC additionally furnishes stable activity with dynamic enlistment engine load and mitigates the insecure and swaying conduct that is coming about during the activity of remunerated Alternator with dynamic engine load.
\end{abstract}

Keywords: Flexible AC transmission systems (FACTS), Static Synchronous Series Compensator (SSSC), PI Controller, Active and reactive power.

\section{Introduction}

A power system is getting more unpredictable and intensely stacked step by step. Prior electric power systems were little and confined. Hence, genuine and reactive power remuneration in transmission line is vital which will improve the soundness of the power framework. Because of high non-straight characteristics of current power framework, the working boundaries changes constantly. Undesirable power contrasts and expanding load over the transmission lines additionally bring about power wavering in the framework. The power systems should have the option to withstand every one of these varieties. Because of such characteristics, motions keep going for few moments (3-20 sec.) in a power framework after a serious flaw happen. It gets critical to soggy out these motions at the earliest opportunity. These superfluous motions may cause immense power quality unsettling influences in power plant and power framework security issues. Considering the soundness conditions the power move capacity is restricted in long transmission. The FACTS gadgets are more beneficial in controlling the power in the transmission lines. In light of the presence of the FACTS controller the power framework strength has been improved under various shortcoming conditions and furthermore improved voltage dependability, reactive power pay and swaying damping. In this paper, static synchronous series compensator (SSSC), one of the sorts of FACTS controllers is inspected. A Static Synchronous Series Compensator (SSSC) is a series controller of FACTS family is associated in series with the transmission lines and used to improve soundness and execution of the framework.

The SSSC controller chiefly relies upon the voltage source converter (VSC) with a few semiconductor and thyristor switches. The SSSC circuit model has a voltage source converter (VSC), DC capacitor and a series coupling transformer. Coupling transformer are associated in series with power framework which couples the SSSC with the transmission line. Principally shunt pay is used predominantly to keep up the necessary voltage profile in the transmission line. While Series compensator can principally work over the consistent state power transmission, greatest power transmission ability, voltage strength and transient soundness. These series controllers are more gainful in pay of reactive power and active power trade as contrast with shunt controller. Likewise, this series pay gives most practical intend to keep up security of power framework. FACTS controllers are arranged in four fundamental classifications: shunt controller, series controller, series-series controller and series-shunt controller. Series associated FACTS gadgets can straightforwardly control active power stream control by changing its line reactance in transmission line. GCSC, SSSC, TCSC are the series FACTS gadgets.

\section{Operating Principles}


The SSSC is a reactive power series compensator utilizing a Voltage-Sourced Converter (VSC) in series with the transmission line, as appeared in Figure 1. This working mode imitates a controlled series reactive remuneration, (for example, gotten with the Thyristor Controlled Series Capacitor (TCSC)), however gives more extensive control range as it can work similarly at capacitive or inductive working areas just as it can work similarly as voltage source. Thyristor based FACTS controllers, as TCSC, depend on impedance control, so they are reliant on the line current. The SSSC can work as a voltage source, which ensures series pay autonomous of the line current.

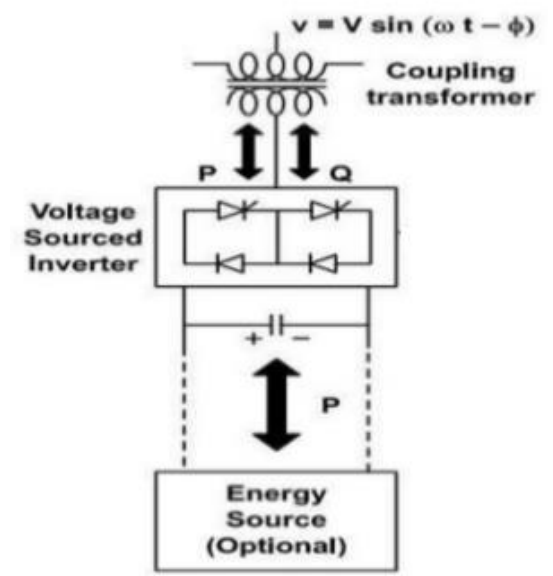

Figure 1 Schematic diagram of SSSC

The VSC inside the SSSC is worked in synchronism with the transmission line current. The voltage created by the VSC is kept in quadrature with the line current, slacking or driving it by 90 degrees. The infusion of a slacking voltage as for the line current imitates a series capacitor, while a main voltage copies a reactor in series with the line. Hence, the SSSC can give either series capacitive or series inductive pay, with no evaluating increment or extra reactive segments, by its innate ability to switch the extremity of the yield voltage it produces. The quadrature connection between the yield voltage of the SSSC and the line current guarantees generously zero genuine power trade between the SSSC and the ac framework, aside from the modest quantity (about $1 \%$ at full yield) needed to renew the inward misfortunes of the converter. This power is drawn from line by the converter, by a little (commonly short of what one degree) deviation from the ideal $90^{\circ}$, to keep the dc capacitor charged without an outside dc power supply.

The line current and the comparing power increment or decline is corresponding to the greatness of series repaying voltage comparative with the voltage across the series line reactance. Customarily, this is communicated by the level of series remuneration, which is characterized as the impedance proportion of the series line reactance to the powerful series capacitor, or, comparably, the plentifulness proportion of the voltage across the series line reactor to the series repaying voltage. The change of the converter voltage adequacy can be accomplished by the control of the dc voltage through the flitting charge or release of the dc capacitor (Figure 2). Then again, the voltage adequacy can be changed inside in the converter by beat width-adjustment, or different strategies, from a fixed (controlled) dc voltage. 


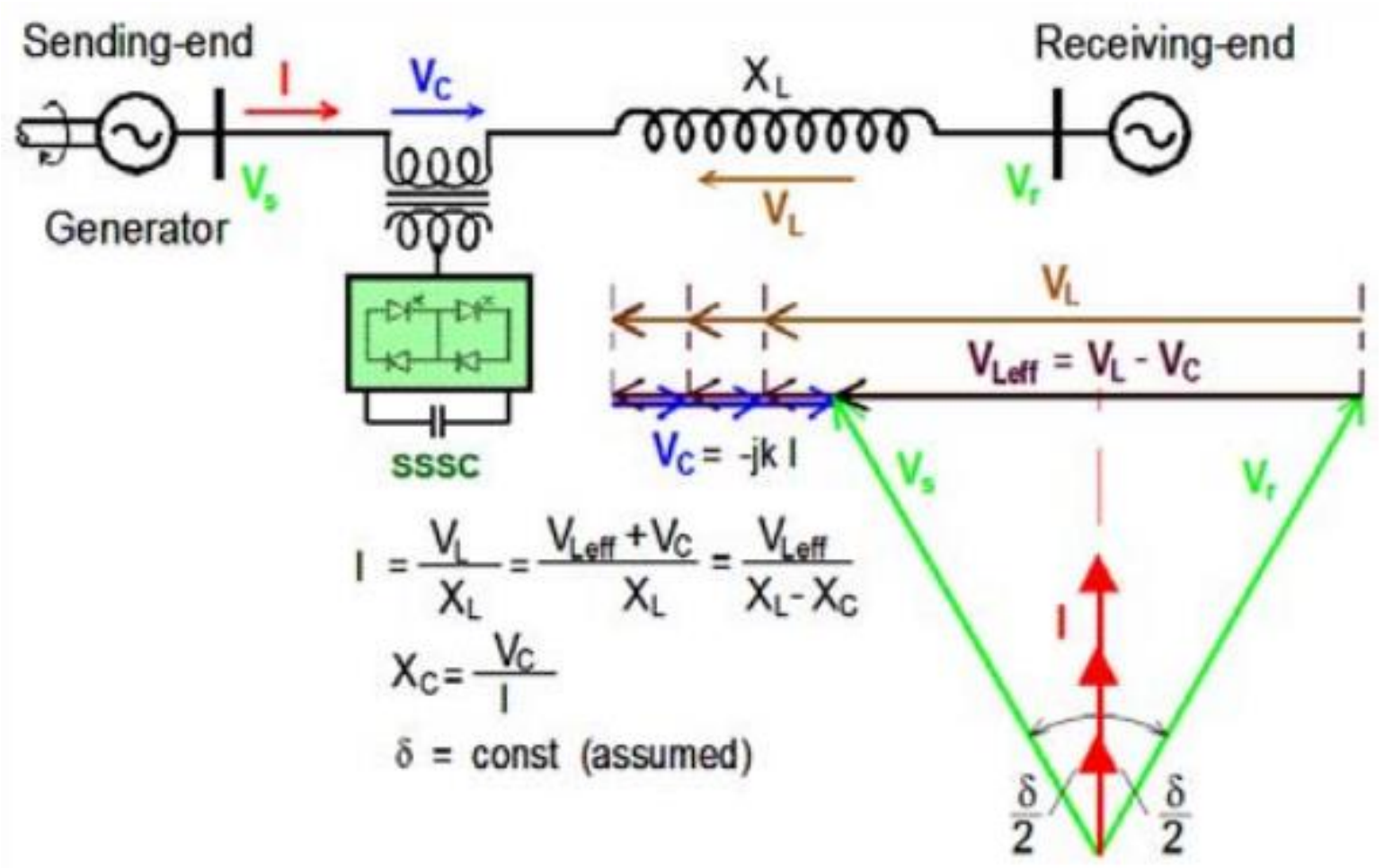

Figure 2 Vector diagram illustration for capacitive and inductive operation modes of the SSSC Steady-State Characteristics of an SSSC

Because of the practically ideal voltage source characteristic of the VSC, the SSSC can give capacitive or inductive repaying voltage free of the line current, up to its predefined voltage rating. Consequently the SSSC can keep up the evaluated greatest capacitive or inductive remunerating voltage in the face of changing line current, hypothetically in the complete working scope of zero to $I_{\max }$, as delineated in Figure 3.

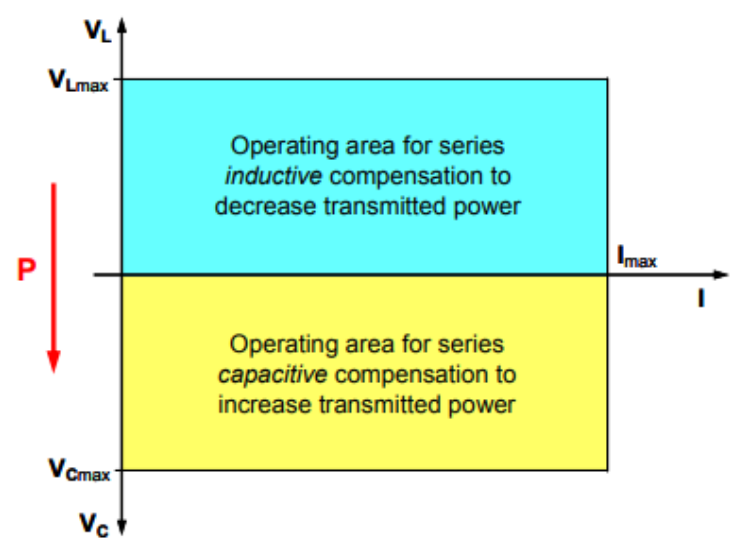

Figure 3 Operating range Characteristics of SSSC

The transmitted power versus transmission angle, i.e., the Pq- $\delta$ characteristic of the SSSC at different per unit estimations of the repaying voltage, $\mathrm{Vq}$, (which might be capacitive or inductive). This figure delineates that the remarkable ability of the SSSC in keeping up the most extreme remunerating voltage autonomous of line current, brings about a wide control range for the sent power at a given transmission point, and give the way to compel the ideal power stream under the state of inadequate or changing transmission point. (The peruser should review that the transmitting voltage created by an ordinary series capacitor changes in extent with the line current and, thus, with the transmission point.) It is discernible that the SSSC is additionally ready to diminish the sent power; in fact, with reasonable rating, it can actually invert the bearing of power flow.

SSSC is better than different FACTS gear and the advantages of utilizing SSSC are:

- Elimination of bulky passive components - capacitors and reactors,

- Symmetric ability in both inductive and capacitive operating modes,

- Possibility of connecting an energy source on the DC side to exchange real power.

\section{LITERATURE REVIEW}


Vishnu Prakash Sharma (2020):In this paper the creator recommended that the transmission line needs controllable pay for power stream control and voltage guideline. This can be achieved by FACTS controllers. Static Synchronous Series Compensator (SSSC) is a series associated FACTS controller, which is fit for giving reactive power remuneration to a power framework. The FACTS gadgets can be utilized for power stream control, circle stream control, load dividing between equal passageways, voltage guideline, and improvement of transient security and moderation of framework motions. A Static Synchronous Series Compensator (SSSC) is an individual from FACTS family which is associated in series with a power framework The yield of a SSSC is series infused voltage, which leads or slacks line current by $90^{\circ}$, accordingly copying a controllable inductive or capacitive reactance. SSSC can be utilized to decrease the comparable line impedance and improve the active power move capacity of the line. In this paper, series pay gave by a SSSC is considered

Anu Rani Sam et al(2019): Power systems are exposed to different kinds of aggravations which cause the issue of losing soundness. The issue of transient solidness is an essential issue. Transient steadiness assessment of huge scope power systems is a very many-sided and profoundly non-direct issue. The fundamental driver of transient steadiness might be because of transmission framework shortcomings, unexpected flaw changes, loss of creating units and line exchanging. So the upgrade of transient steadiness is basic for a protected power framework activity. Transient soundness of a framework alludes to the solidness when exposed to huge unsettling influences, for example, blames and exchanging of lines. Transient dependability of the framework can be improved by expanding the framework voltage, expanding the X/R proportion, expanding the quantity of equal lines among focuses and placement of the FACTS gadgets. The FACTS controller can improve the voltage dependability, consistent state and transient soundness of a power framework. UPFC (Unified Power Flow Controller) and SSSC (Static Synchronous Series Compensator) can improve the transient steadiness of the framework. Recreation of transient soundness without and with FACTS gadget was finished utilizing MATLAB based program and the investigation is performed on IEEE 6 transport framework.

\section{PROPOSED METHODOLOGY}

A SSSC is a strong state voltage sourced converter (VSC), which produces a controllable AC voltage, and associated in series to power transmission lines in a power framework. SSSC gives the virtual pay of transmission line impedance by infusing the controllable voltage $(\mathrm{Vq})$ in series with the transmission line. $\mathrm{Vq}$ is in quadrature with the line current, and copies an inductive or a capacitive reactance in order to impact the power stream in the transmission lines. The virtual reactance embedded by $\mathrm{Vq}$ impacts electric power stream in the transmission lines free of the greatness of the line flow. The variety of Vq is performed by methods for a VSC associated on the auxiliary side of a coupling transformer. The remuneration level can be controlled progressively by changing the greatness and extremity of $\mathrm{Vq}$ and the gadget can be worked both in capacitive and inductive mode. The VSC utilizes constrained commutated power electronic gadgets to create an AC voltage from a DC voltage source. A capacitor associated on the DC side of the VSC acts as a DC voltage source. To keep the capacitor charged and to give transformer and VSC misfortunes, a little active power is drawn from the line. As introduced in VSC utilizing IGBT-based PWM inverters is utilized in the current investigation.

A SSSC includes a voltage source inverter and a coupling transformer that is utilized to embed the ac yield voltage of the inverter in series with the transmission line. The size and period of this embedded ac repaying voltage can be quickly changed by the SSSC controls.

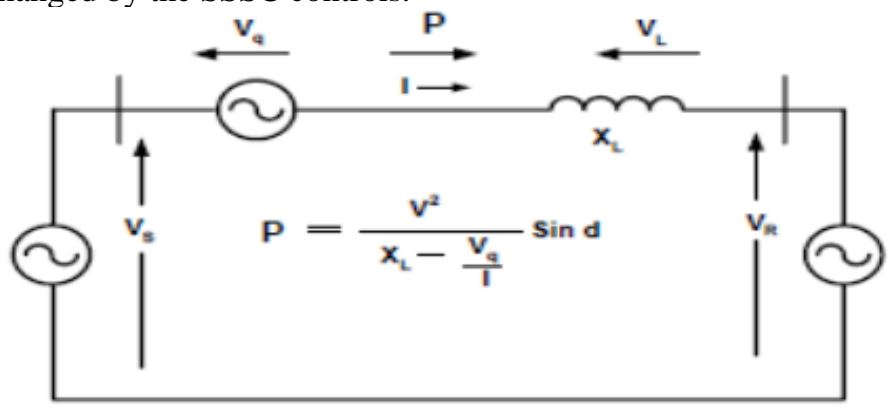

Figure 4Elementary two-machine system with an SSSC

The power flow $(\mathrm{P})$ in the transmission line of system is given by,

$$
\mathrm{P}=\mathrm{VI} \cos \frac{\delta}{2}=\frac{V, V c}{X} \cos \delta+\frac{V^{2}}{X} \sin \delta
$$

The reactive power supplied at the two end of the line are equal (Q).the expression for $\mathrm{Q}$,

$$
\mathrm{Q}=\mathrm{VI} \sin \frac{\delta}{2}=\frac{V, V c}{X} \sin \frac{\delta}{2}+\frac{V^{2}}{X}(1-\cos \delta)
$$


The SSSC injects the compensatingvoltage in series with the line independent of the line current. The communicated power $\mathrm{Pq}$, in this way turns into a parametric capacity of the infused voltage, and can be communicated as follows.

$$
P_{q}=\frac{V^{2}}{X_{L}} \sin \delta+\frac{V V_{q}}{X_{L}} \cos \frac{\delta}{2}
$$

The SSSC, consequently can build the communicable power, and furthermore decline it, essentially by switching the extremity of the infused ac voltage. The turned around $\left(180^{\circ}\right.$ stage moved) voltage adds straightforwardly to the reactive voltage drop of the line as though the line impedance was expanded. Moreover, if the infused voltage is made bigger than the voltage intrigued across the uncompensated line by the sending-and getting end systems, that is in the event that $|\mathrm{Vq}|>|\mathrm{V} 1-\mathrm{V} 2|$, at that point the power stream can. Aside from the steady activity of the framework with both positive and negative power streams, it can likewise be seen that the SSSC has an astounding (sub-cycle) reaction time and that the progress.

\section{Two Machine System Modeling with SSSC}

Contingent on the framework conditions and the heaps entering/getting out, the infused voltage and current to the circuit are changed so in this manner SSSC looks like variable reactance. The series converter of SSSC is appeared in figure 5 which is utilized by SSSC to react to the dynamic and transient changes made in framework. The framework comprises of two creating machines alongside transmission line and burden as appeared in figure. The compensator is given a DC voltage source which helps in taking care of or engrossing the active and reactive power from the framework

The control circuit in which the different sides of the converter are associated with AC framework on one side and capacitor and battery on the opposite side. The battery we expected here is a DC source. In the event that any powerful change happens in the framework the SSSC circuit works as per the control circuit. The converter changes the energy of battery over to the ac structure and on infusing this voltage to the circuit the progressions will be damped fittingly.

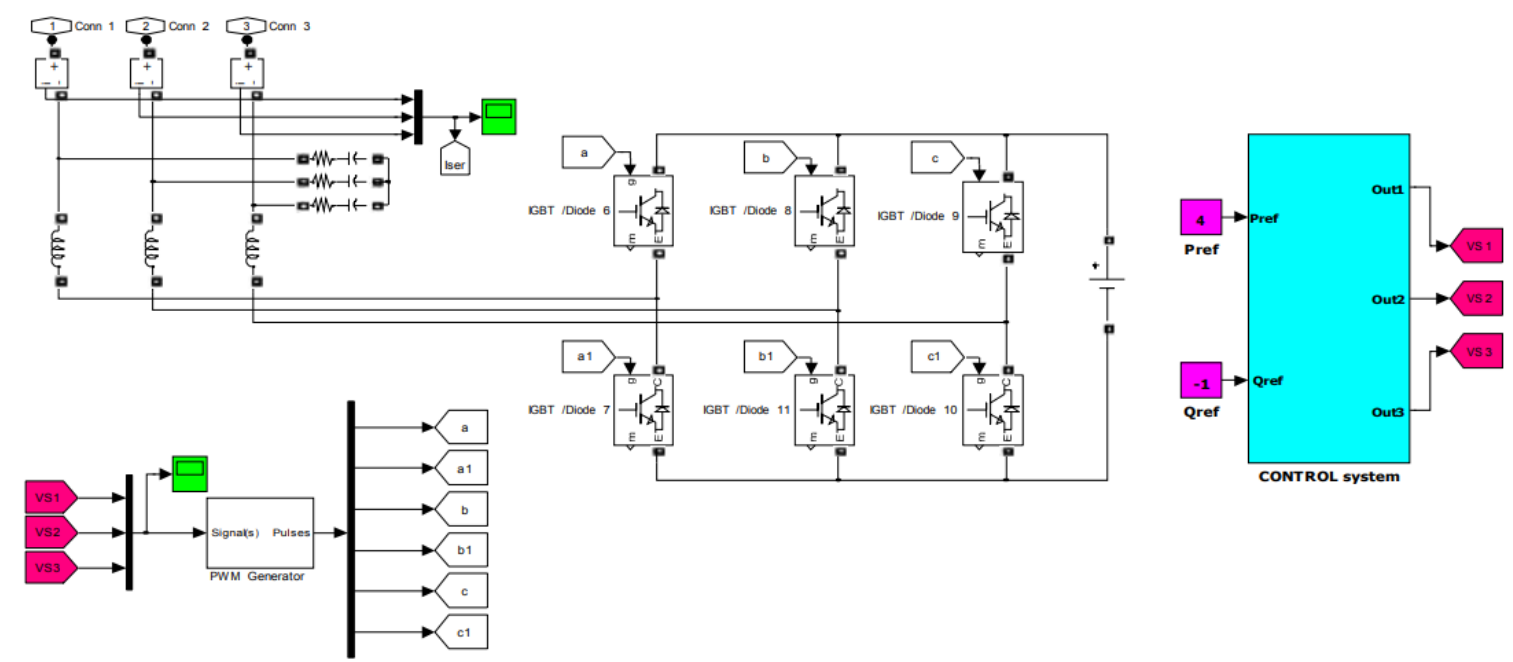

Figure 5 Convertor of Static Synchronous Series Compensator

The control circuit is utilized to control the active and reactive powers of bus-2. For controlling the powers, first, testing from the voltage and current is done and changed to the dq0 values. Utilizing the voltage and current in $\mathrm{dq} 0$ references the active and reactive powers of bus- 2 are determined and contrasted and the decided reference. The blunder signal delivered is given to the PI controllers. We can attempt to achieve the zero sign blunder by changing the boundaries of the PI controllers with the end goal that powers can follow the reference powers exactly. At that point, the yield of the controllers is changed to the abc reference and is given to the PWM. 


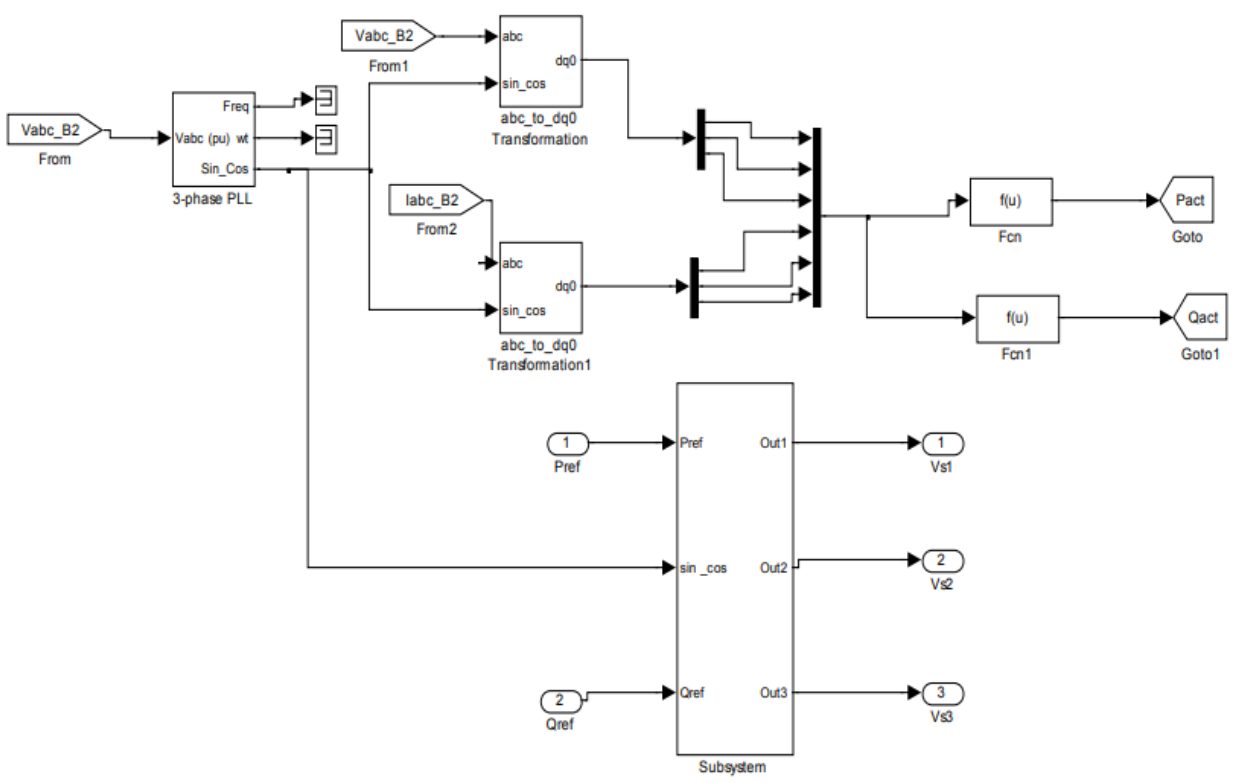

Figure 6 Simulated control circuit of SSSC

Active and reactive powers infused by power plants 1 and 2 to the power framework are introduced in per unit by utilizing base boundaries $\mathrm{Sb}=100 \mathrm{MVA}$ and $\mathrm{Vb}=500 \mathrm{KV}$, which active and reactive powers of power plants 1 and 2 are (24-j3.8) and (15.6-j0.5) in per unit, separately.

\section{Simulation results with SSSC}

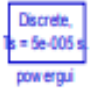

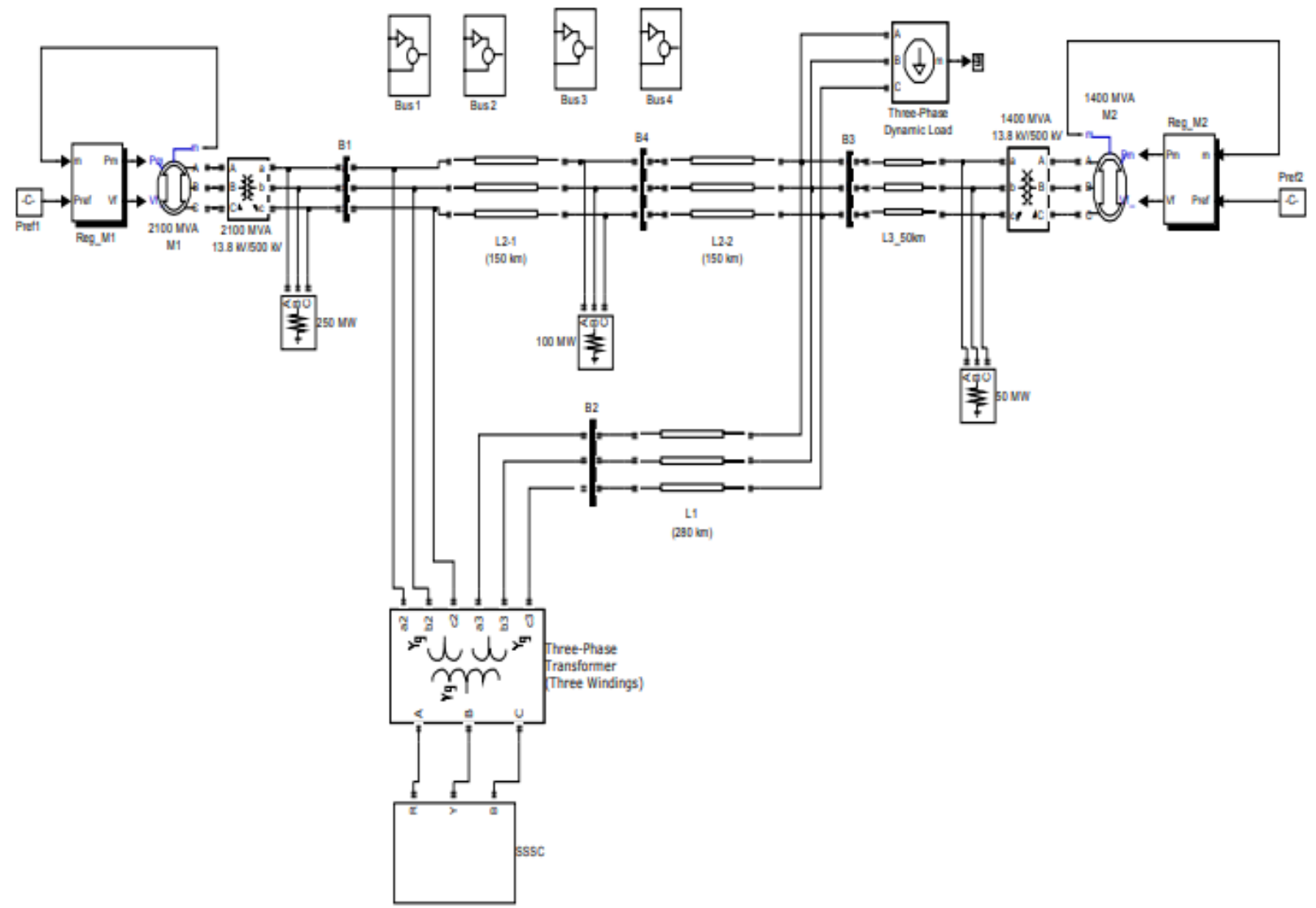

Figure 7 Simulation Diagram with SSSC

To begin with, power framework with two machines and four buses has been recreated in MATLAB climate, and afterward powers and voltages in all buses have been gotten. The outcomes have been given in Table. 
Utilizing got results bus-2 has been chosen as an up-and-comer bus to which the SSSC be introduced. In this way, the reproduction results have been centered focused on bus-2.
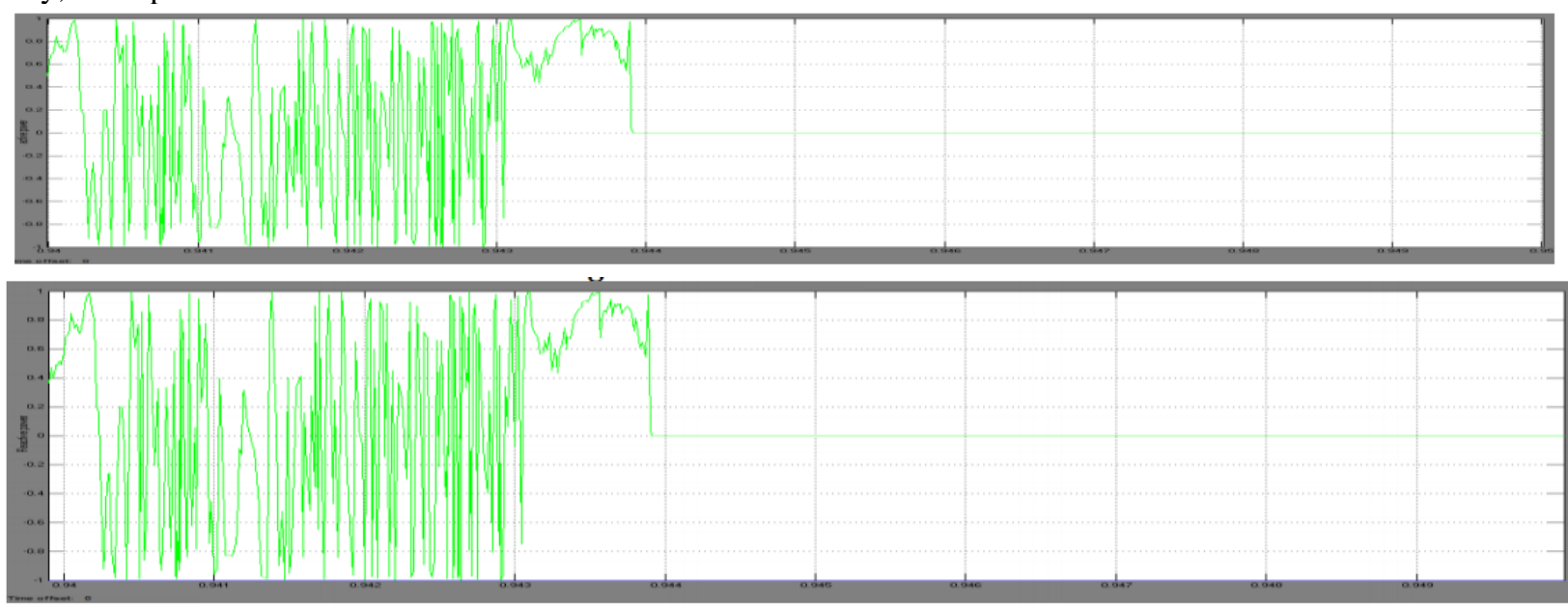

Figure8. Active Power and Reactive power with SSSC
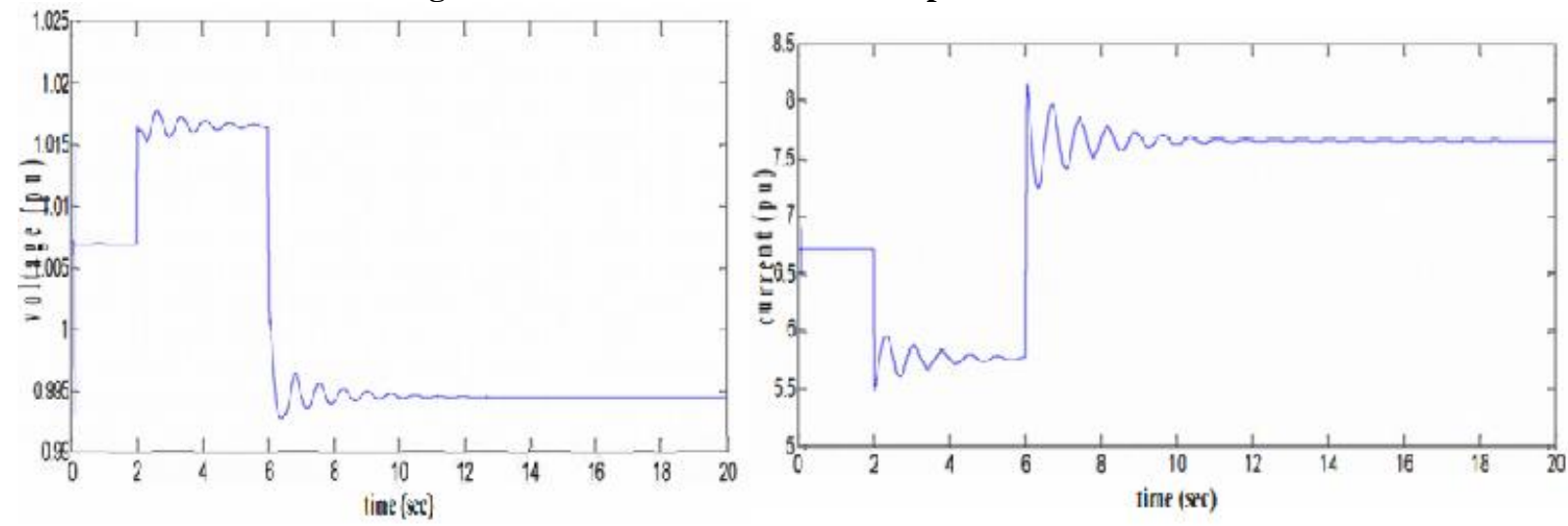

Figure 9 Voltage and Current at bus 2 with SSSC

At the point when SSSC is placed at bus-2 the principle part of SSSC is to control the active and reactive power.as appeared in figure 8 active power swaying are damped out and voltage esteem is in 1pu consistent, active power damping time is less in framework with SSSC contrasted with framework without SSSC the reactive power damping time is diminished contrasted with framework without SSSC. Figure 9 shows the voltage and current waveform are sinusoidal and henceforth unsettling influence eliminated.

\section{CONCLUSION}

It has been discovered that the SSSC is fit for controlling the progression of power at an ideal point on the transmission line. It is additionally seen that the SSSC infuses a quick changing voltage in series with the line regardless of the size and period of the line current. In view of got reenactment results the presentation of the SSSC has been analyzed in a multi-machine framework, and uses of the SSSC will be stretched out in future to a perplexing framework to research the issues identified with the different methods of power swaying in the power systems. This paper, the SSSC is utilized to moist power swaying on a power framework following a three-stage flaw Based on got recreation results the presentation of the SSSC has been inspected in a basic two-machine framework essentially on the chose bus-2, and utilizations of the SSSC will be stretched out in future to a complex and multi machine framework to research the issues identified with the different methods of power wavering in the power systems.

\section{REFERENCES}

1. Vishnu Prakash Sharma (2020), "Static Synchronous Series Compensator (SSSC): An approach for reactive power compensation for the transmission system". 2020 IJIRT. Volume 1 Issue 10. ISSN: 234960023

2. Anu Rani Sam, P.Arul (2019), “Transient Stability Enhancement of Multi-machine Power System Using UPFC and SSSC". International Journal of Innovative Technology and Exploring Engineering (IJITEE) ISSN: 2278-3075, Volume-3, Issue-5, October 2019 
3. SEN,K.K.: “ SSSC-“ Static Synchronous Series Compensator: Theory, Modeling and applications”, IEEE Trans.,2017 PD-13.

4. Habibur Rahman 1, Jewel Rana2, Harun-Or-Rashid, "Power system stability improvement by using SSSC with Power system controller", International Journal of Science, Engineering \& Technology Research (IJSETR), Volume 1, Issue 6, December- 2018

5. Mohammed Abdul Khader Aziz biabani, Mohdakram, Ikramahmedshareef, Power System Stability Enhancement using Static Synchronous Series Compensator, International conference on Signal Processing, Communication, Power and Embedded System (SCOPES)-2016, 978-1-5090-46201/16/\$31.00 @2018 IEEE.

6. Swain S, Mahapatra S, Panda S. Design of the optimized sssc based facts controller. Int J Electron Electrical Eng 2019.

7. Ghandhari M, Andersson G, Zanetta AI, Hiskens. Control Lyapunov functions for controllable series devices. IEEE Trans Power Syst 2001;16-4:689-94

8. M.S. Castro, H.M. Ayres, V.F. da Costa, C.L.P. da Silva, Impacts of the SSSC control modes on smallsignal transient stability of a power system, Electr. Power Syst. Res. 77 (2017) 1-9.

9. D. Menniti, A. Pinnarelli, N. Scordino, N. Sorrentino, Using a FACTS device controlled by a decentralised control law to damp the transient frequency deviation in a deregulated electric power system, Electr. Power Syst. Res. 72 (2004) 289-298.

10. Chintan R Patel,Sanjay N Patel and DrAxay J Mehta."SSSC : An approach for Reactive power Cpmpensation for transmission line. B.V.M Engineering College,V.Vnagar,Gujarat.

11. B.N.Singh, A.Chandra, K.Al-Haddad and B.Singh, "Performance of sliding-mode and fuzzy controllers for a static synchronous series compensator, "IEE Proceedings onhe no. 19990072, IEE, 2018.

12. H. Taheri, S. Shahabi, Sh. Taheri and A. Gholami (2019) "Application of Synchronous Static Series Compensator (SSSC) on Enhancement of Voltage Stability and Power Oscillation Damping", IEEE Transactions on Power System, pp. 533-539. 